\title{
Fuzzy Arithmetical Modeling of a Steam Turbine and a Boiler System
}

\author{
Wan Munirah Wan Mohamad ${ }^{a}$, Tahir $\operatorname{Ahmad}^{a, b}$, \\ Niki Anis Ab Karim ${ }^{a, b}$ and Azmirul Ashaari ${ }^{a}$ \\ ${ }^{a}$ Department of Mathematical Sciences, Faculty of Science, Universiti \\ Teknologi Malaysia
}

81310 UTM, Skudai, Johor, Malaysia

${ }^{b}$ Centre for Sustainable Nanomaterials, Ibnu Sina Institute for Scientific and

Industrial Research, Universiti Teknologi Malaysia

81310 UTM, Skudai, Johor, Malaysia

E-mail(corresp.): tahir@ibnusina.utm.my

Received April 27, 2017; revised December 18, 2017; accepted December 19, 2017

\begin{abstract}
The steam turbine and a boiler are important components of a power generation plant. Improved efficiency of a power plant leads to increase of energy production and less waste. In this paper, a model of the power plant as a multivariable system using fuzzy arithmetic which is based on the Transformation Method (TM) is presented. The analytical solution is used to evaluate the state space model. The $\mathrm{TM}$ is then used to quantify the influence of each parameter and their gain factors are calculated to allow estimation of relative measures of uncertainty. The method is applied to a boiler and a steam turbine systems for simulation, analysis and indication of TM's efficiency. The efficiency of TM is presented in this paper.
\end{abstract}

Keywords: fuzzy arithmetic, steam turbines, boiler.

AMS Subject Classification: 97F90.

\section{Introduction}

One of the most frequently-researched subjects in thermal energy is the powergeneration plant. A combined-cycle power plant is a large-scale electrical power generation plant in which electricity is obtained from both gas and steam turbines. Energy is transferred in the form of heat or gaseous flow through each turbine to produce electricity [12]. Furthermore, additional electricity is produced using wasted heat which may be found in exhaust gases from turbines or other parts of the system. Effort is also taken to reduce losses of energy. 
A steam turbine has complex features in order to increases thermal efficiency $[1,11]$. This complexity is also the reason why nonlinear analytical model has been developed to study transient dynamics of steam turbine. Such a model can be used for control, simulation and monitoring of the state of the system.

The furnace described in [12] is chosen for this research. A furnace is a thermal device in which water or air is heated and later circulated throughout the system [9]. The furnace is an important subsystem of a boiler in combinedcycle power plant. The system is usually in temperate countries with four seasons. The most common fuel sources for modern furnaces are coal, liquefied petroleum gas, and fuel oil.

Another component of a boiler discussed in this paper is the reheater. The reheater is an important component in a high-capacity power plant. Heat exchange occurs whereby temperature and pressure will be reduced before entering in low speed turbine [10]. The temperature drops in reheater due to pressure loss.

A boiler and a steam turbine system have complex features affecting thermal efficiency. In this regard, no mathematical model can precisely describe such a complicated process. Inaccuracy is inherent in the developed model due to uncertain parameters. The lack of accurate modeling causes many difficulties in deciding control strategies and a measure for model fitness is required for better overall performance.

Previous research by Izaz Ullah Khan [8] only describes the Inverse Feedback Fuzzy State Space Model (FFSSM) for the steam turbine model. The algorithm is used to maximize the power production with optimal input parameters. The inverse modeling approach was used to determine the optimal operating conditions. The method was used at the three stages of the steam turbine.

Graph was used in [7] to model the boiler system. The boiler system consists of subsystems such as furnace, superheater, drum, riser and reheater. These subsystems are represented as vertices and the interconnections between subsystems are associated with edges of the graph. Initially, the input-output variables for the subsystems are identified using a state space approach. It is used as an initial for the development of the fuzzy model of the system.

The transformation method is carried out to reduce the number of parameters. It is described in Section 2 below.

\section{The transformation method (TM)}

There are two types of TM: general and reduced forms. Both types are acceptable for simulation and analysis of systems with uncertain parameters. They can be used to evaluate and simulate static or dynamical systems with fuzzyvalued parameters. The equations for coefficients in general TM are proposed in $[2,3,4,5]$. 


\subsection{Simulation of a system with uncertain parameters: general transformation method}

The system's uncertain parameters can be represented by fuzzy numbers $\tilde{p}_{i}$ where $i=1,2, \ldots, n$,

$$
\begin{aligned}
& P_{i}=X_{i}^{(0)}, X_{i}^{(1)}, \ldots, X_{i}^{(m)}, \quad X_{i}^{(j)}=\left[a_{i}^{(j)}, b_{i}^{(j)}\right]=c u t_{\mu j}\left(\tilde{p}_{i}\right), \quad a_{i}^{(j)} \leq b_{i}^{(j)}, \\
& i=1,2, \ldots, n, \quad j=0,1, \ldots, m .
\end{aligned}
$$

A fuzzy parameterized model is expected to show non-monotonic behavior with respect to $n$, with $n>1$. Only the intervals $X_{i}^{(j)}, i=1,2, \ldots, n$ for $j=0,1, \ldots, m-2$, are considered for the transformation scheme. The intervals are then transformed into arrays $\hat{X}_{i}^{(j)}$ in the form

$$
\begin{aligned}
& \hat{X}_{i}^{(j)}= \underbrace{\left.\left(\gamma_{1, i}^{(j)}, \gamma_{2, i}^{(j)}, \ldots, \gamma_{(m+1-j), i}^{(j)}\right), \ldots,\left(\gamma_{1, i}^{(j)} \gamma_{2, i}^{(j)}, \ldots, \gamma_{(m+1-j), i}^{(j)}\right)\right)}_{(m+1-j)^{i-j}}, \\
& \gamma_{l, i}^{(j)}= \underbrace{\left(c_{l, i}^{(j)}, \ldots, c_{l, i}^{(j)}\right)}_{(m+1-j)^{n-i} \text { elements }} \cdot \\
& c_{l, i}^{(j)}= \begin{cases}0, & a_{i}^{(j)} \text { for } l=1, j=0,1, \ldots, m, \\
\frac{1}{2}\left(c_{l-1, i}^{(j+1)}+c_{l, i}^{(j+1)}\right), & \text { for } l=2,3, \ldots, m-j, j=0,1, \ldots, m-2, \\
0, & b_{i}^{(j)} \text { for } l=m-j+1, j=0,1, \ldots, m,\end{cases}
\end{aligned}
$$

The arithmetical expression of $F$ is given in the form:

$$
\tilde{q}=F\left(\tilde{p}_{1}, \tilde{p}_{2}, \ldots, \tilde{p}_{n}\right) .
$$

The expression is evaluated separately for up to $2^{n}$ combinations using conventional arithmetic for crisp numbers. The result can be expressed in decomposed and transformed forms by the combination $\hat{Z}^{(j)}$ for $j=0,1, \ldots, m$. The $k$-th element of ${ }^{k} \hat{Z}^{(j)}$ of the array $\hat{Z}^{(j)}$ is given as

$$
{ }^{k} \hat{Z}^{(j)}=F\left({ }^{k} \hat{x}_{1}^{(j)},{ }^{k} \hat{x}_{2}^{(j)}, \ldots,{ }^{k} \hat{x}_{n}^{(j)}\right), \quad k=1,2, \ldots, 2^{n} .
$$

Finally, the fuzzy-valued $\tilde{q}$ of the expression can be obtained in decomposed form

$$
Z^{(j)}=\left[a^{(j)}, b^{(j)}\right], j=0,1, \ldots, m
$$

by transforming $\hat{Z}^{(j)}$ using the following recursive formulas:

$$
\begin{aligned}
& a^{(j)}=\min _{k}\left(a^{(j+1)},{ }^{k} \hat{z}^{(j)}\right), \quad b^{(j)}=\max _{k}\left(b^{(j+1)}, \quad{ }^{k} \hat{z}^{(j)}\right), j=0,1, \ldots, m-1, \\
& a^{(m)}=\min _{k}\left({ }^{k} \hat{z}^{(m)}\right)=\max _{k}\left({ }^{k} \hat{z}^{(m)}\right)=b^{(m)} .
\end{aligned}
$$




\subsection{Analysis of a system with uncertain parameters: general trans-} formation method

The coefficients $\eta_{i}^{(j)}$, for $i=1,2, \ldots, n$ and $j=0,1, \ldots, m-1$, are determined:

$$
\begin{aligned}
& \eta_{i}^{(j)}=\frac{1}{(m-j+1)^{n-1}\left(b_{i}^{(j)}-a_{i}^{(j)}\right)} \sum_{k=1}^{(m-j+1)^{n-i}} \sum_{l=1}^{(m-j+1)^{i-1}}\left({ }^{s_{2}} \hat{z}^{(j)}-{ }^{s_{1}} \hat{z}^{(j)}\right), \\
& s_{1}(k, l)=k+(l-1)(m-j+1)^{n-i+1}, \\
& s_{2}(k, l)=k+[(m-j+1) l-1](m-j+1)^{n-i} .
\end{aligned}
$$

The values $a_{i}^{(j)}$ and $b_{i}^{(j)}$ denote the lower and upper bound of the interval $X_{i}^{(j)}$ and ${ }^{k} \hat{z}^{(j)} k$-th are the elements of the array $\hat{Z}^{(j)}$. The coefficients $\eta_{i}^{(j)}$ are gain factors from uncertainty in the $i$-th parameter with respect to the uncertainty of output $z$ with membership level $\mu_{j}$. Mean gain factors $\eta_{i}^{(j)}$ are obtained such as:

$$
\overline{\eta_{i}}=\sum_{j=1}^{m-1} \mu_{j} \eta_{i}^{(j)} / \sum_{j=1}^{m-1} \mu_{j}
$$

Finally, the degree of influence $\rho_{i}$ is determined for $i=1,2, \ldots, n$ using

$$
\rho_{i}=\frac{\sum_{j=1}^{m-1} \mu_{j}\left|\eta_{i}^{(j)}\left(a_{i}^{(j)}+b_{i}^{(j)}\right)\right|}{\sum_{q=1}^{n} \sum_{j=1}^{m-1} \mu_{j}\left|\eta_{q}^{(j)}\left(a_{q}^{(j)}+b_{q}^{(j)}\right)\right|}, \quad \sum_{i=1}^{n} \rho_{i}=1 .
$$

\subsection{FAMOUS software}

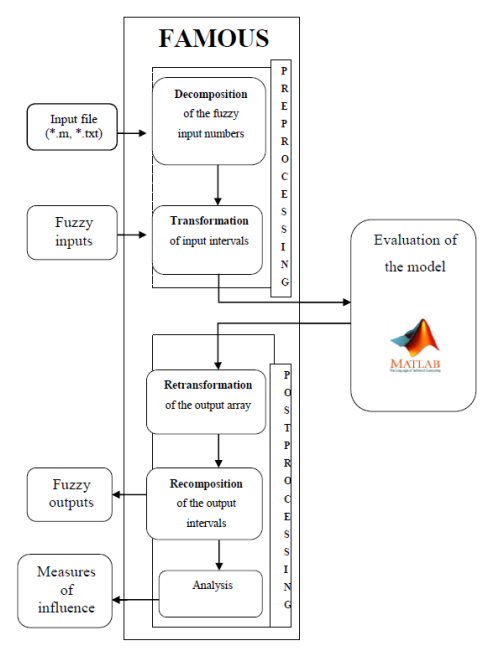

Figure 1. Structure of the software FAMOUS [6]. 
In this study, a software package by [6] called Fuzzy Arithmetical Modeling of Uncertain Systems (FAMOUS) (see Figure 1) is used to simulate and analyze the model of the boiler and steam turbine. FAMOUS is a toolbox that provides a framework to handle parametric uncertainties in systems analysis. It uses the transformation method in Section 2.1-2.2 to compute solutions for a given system.

\section{Application to a Steam Turbine System}

The equation (3.1) describes the state, and equation (3.2) describes the output of the steam turbine. The state variables of the steam turbine model are steam energy per unit volume $\left(\mathrm{X}_{\mathrm{o}}^{\prime}\right)$, outlet steam flow $\left(\mathrm{w}_{\mathrm{ou}}{ }^{\prime}\right)$ and steam density $\left(\rho_{\mathrm{ou}}^{\prime}\right)$. The output variables are outlet steam density $\left(\mathrm{p}_{\mathrm{ou}}\right)$, outlet steam temperature $\left(\mathrm{T}_{\mathrm{ou}}\right)$ and mechanical power development $(\mathrm{P})$ [12]. Thus, the state space equation is given as in [11]:

$$
\begin{aligned}
& {\left[\begin{array}{c}
X_{o}{ }^{\prime} \\
w_{o u}{ }^{\prime} \\
\rho_{\text {ou }}{ }^{\prime}
\end{array}\right]=\left[\begin{array}{ccc}
0 & -h_{o} / v & 0 \\
-\frac{C}{h_{o} \tau_{s}} & 0 & 0 \\
0 & 0 & -\frac{C}{r V}
\end{array}\right]\left[\begin{array}{c}
X_{o} \\
w_{o u} \\
\rho_{o u}
\end{array}\right]} \\
& +\left[\begin{array}{ccc}
\frac{h_{o}}{v} & -\frac{w_{i n}}{v} \cdot \frac{c_{p}}{R \rho_{o}} \cdot \frac{T_{i n}}{T_{o u}} & \frac{w_{i n} c_{p}}{v} \\
1 / \tau_{s} & 0 & 0 \\
1 / v & 0 & 0
\end{array}\right]\left[\begin{array}{c}
w_{i n} \\
P_{i n} \\
T_{i n}
\end{array}\right], \\
& {\left[\begin{array}{c}
p_{\text {ou }} \\
T_{\text {ou }} \\
P
\end{array}\right]=\left[\begin{array}{ccc}
r R T_{o} / h_{o} & 0 & 0 \\
\eta^{\eta}\left(\frac{\gamma-1}{\gamma}\right) & 0 & \frac{\left(c_{p} T_{o u-} h_{o u}\right) r^{\eta} \infty\left(\frac{\gamma-1}{\gamma}\right)}{r c_{p} p_{o}} \\
c_{p} \rho_{o} & 0
\end{array}\right]\left[\begin{array}{c}
X_{o} \\
w_{\text {ou }} \\
\rho_{\text {ou }}
\end{array}\right] \text {, }}
\end{aligned}
$$

where

$$
C=A \sqrt{2 \eta_{\infty} m \rho_{o}\left(r^{\left(\frac{2}{m}\right)}-r^{\left(\frac{m+1}{m}\right)}\right) /\left((m-1) p_{o}\right)} .
$$

The reduction method is applied to the steam turbine in order to reduced computing time. By solving the ordinary differential equations, the output $P_{\text {ou }}$ is selected from equation (3.2)

$$
P_{\text {ou }}=r R T_{o} X_{o} / h_{o}
$$

From equation (3.3), $X_{o}$ is identified as

$$
\begin{aligned}
& X_{o}{ }^{\prime}=-\frac{h_{o}}{v} w_{o u}+\frac{h_{o}}{v} w_{i n}-\frac{w_{i n}}{v} \frac{c_{p}}{R \rho_{o}} \frac{T_{i n}}{T_{o u}} P_{i n}+\frac{w_{i n} c_{p}}{v} T_{i n}, \\
& \int X_{o}^{\prime}=\int-\frac{h_{o}}{v} w_{o u}+\frac{h_{o}}{v} w_{i n}-\frac{w_{i n}}{v} \frac{c_{p}}{R \rho_{o}} \frac{T_{i n}}{T_{o u}} P_{i n}+\frac{w_{i n} c_{p}}{v} T_{i n} d t, \\
& X_{o}=-\frac{h_{o}}{v} w_{\text {ou }}(t)+\frac{h_{o}}{v} w_{i n}(t)-\frac{w_{i n}}{v} \frac{c_{p}}{R \rho_{o}} \frac{T_{i n}}{T_{o u}} P_{i n}(t)+\frac{w_{i n} c_{p}}{v} T_{i n}(t)+c .
\end{aligned}
$$


Substituting (3.4) into (3.3) gives

$$
P_{\text {ou }}=\frac{r R T_{o}}{h_{o}}\left[-\frac{h_{o}}{v} w_{\text {ou }}(t)+\frac{h_{o}}{v} w_{\text {in }}(t)-\frac{w_{\text {in }}}{v} \frac{c_{p}}{R \rho_{o}} \frac{T_{i n}}{T_{o u}} P_{\text {in }}(t)+\frac{w_{\text {in }} c_{p}}{v} T_{i n}(t)+c\right] .
$$

By using FAMOUS, the input parameters of the steam turbine system (HP, IP and LP) are expressed by the fuzzy model parameters $p_{1}$ (Inlet steam flow from boiler superheat section), $p_{2}$ (Inlet steam pressure), $p_{3}$ (Inlet steam flow temperature), $p_{4}$ (Inlet steam flow enthalpy) and $p_{5}$ (Inlet steam flow density). The membership functions are derived from quasi-Gaussian distributions, as illustrated in Figures 2-4.

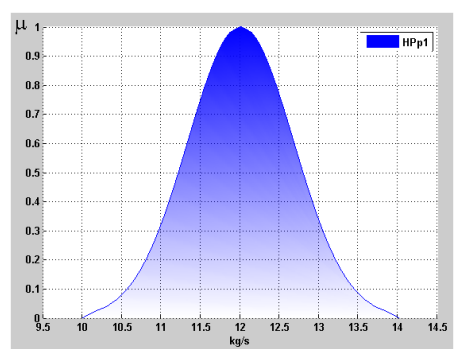

(a)

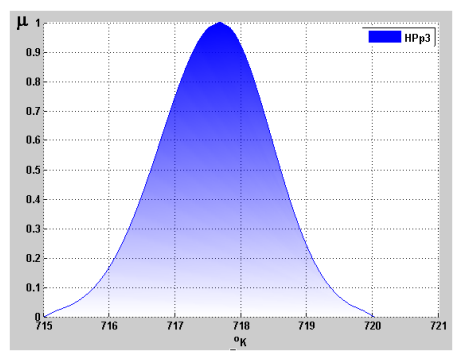

(c)

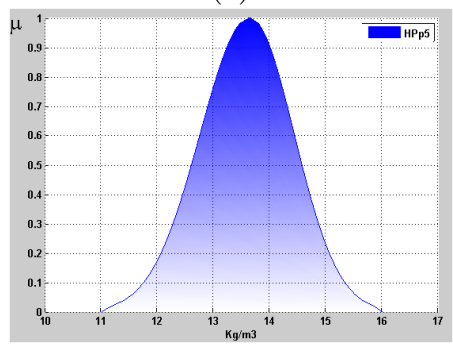

(e)

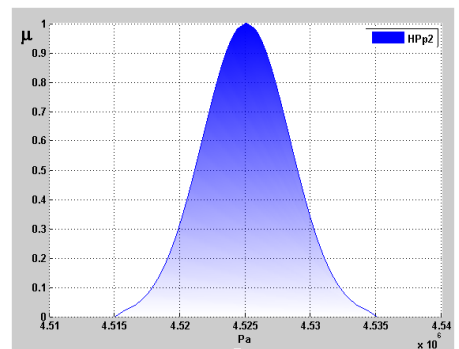

(b)

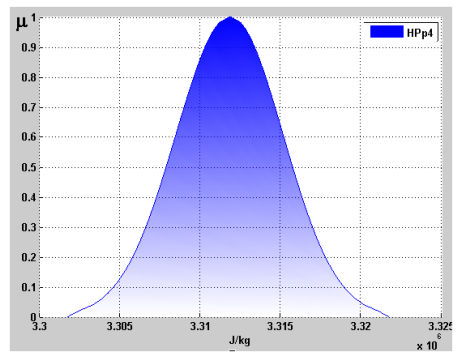

(d)

Figure 2. Fuzzy input parameters of high-pressure section of a steam turbine system (a) $p_{1}$ (Inlet steam flow from boiler superheat section), (b) $p_{2}$ (Inlet steam pressure), (c) $p_{3}$ (Inlet steam flow temperature), (d) $p_{4}$ (Inlet steam flow enthalpy) and (e) $p_{5}$ (Inlet steam flow density).

The output variable $\tilde{q}=P_{\text {ou }}$ is obtained for each section of the steam turbine. Figure 5 shows the fuzzy output $P_{\text {ou }}$ for HP, IP and LP sections of 


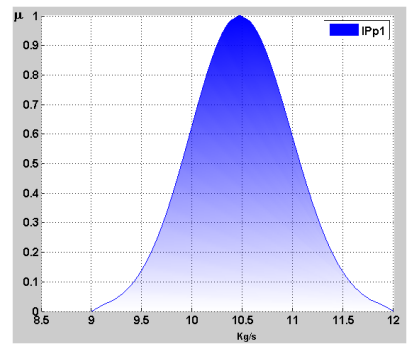

(a)

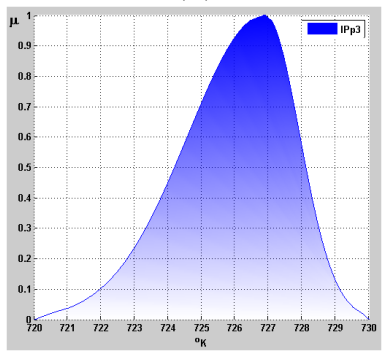

(c)

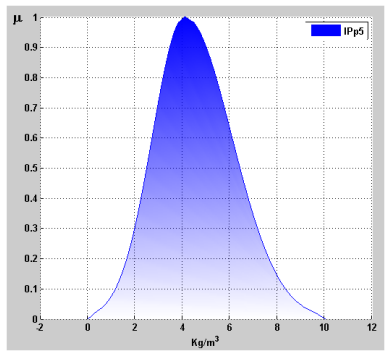

(e)

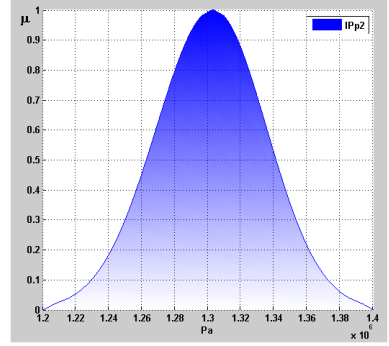

(b)

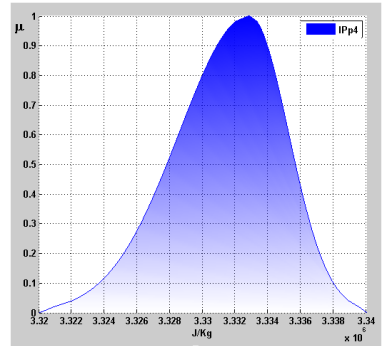

(d)

Figure 3. Fuzzy input parameters of intermediate-pressure section of a steam turbine system (a) $p_{1}$ (Inlet steam flow from boiler superheat section), (b) $p_{2}$ (Inlet steam pressure), (c) $p_{3}$ (Inlet steam flow temperature), (d) $p_{4}$ (Inlet steam flow enthalpy) and (e) $p_{5}$ (Inlet steam flow density).

the system. The results do not show significant variations when compared to the original symmetric quasi-Gaussian distribution, namely $p_{1}, p_{2}, p_{3}, p_{4}$ and $p_{5}$ of the steam turbine.

Given in Figure 6, the overall uncertainty of the model output in high pressure section is induced by the uncertainty in $\rho_{2}$ (Inlet steam pressure) with a degree of influence of $49 \%$. The degree of output uncertainty influenced by $\rho_{1}$ is only $32 \%$ and for $\rho_{3}$ is just $18 \%$. The rest, $\rho_{4}$ and $\rho_{5}$ have such low percentages of influence and are considered negligible.

As for the intermediate-pressure section: the uncertainty from $\rho_{2}$ shows high influence on the overall uncertainty of the system, at $47 \%$. The uncertainties of $\rho_{1}$ and $\rho_{3}$ show low impact, with $34 \%$ and $18 \%$ respectively. The influence of parameters $\rho_{4}$ and $\rho_{5}$ are considered negligible. 


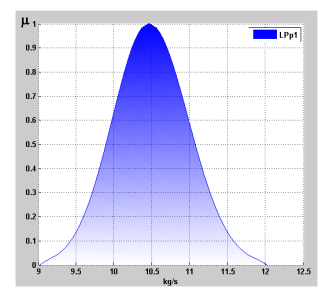

(a)

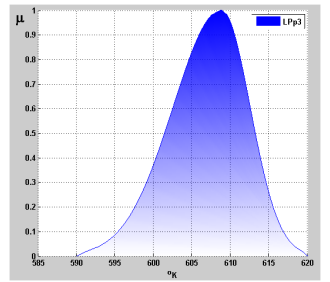

(c)

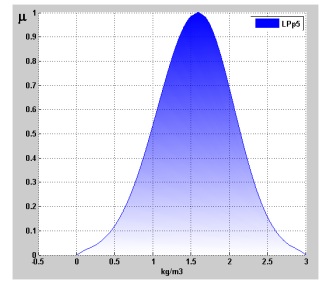

(e)

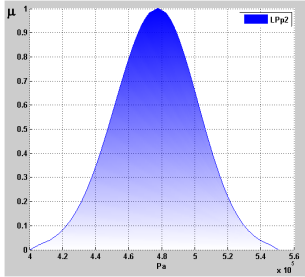

(b)

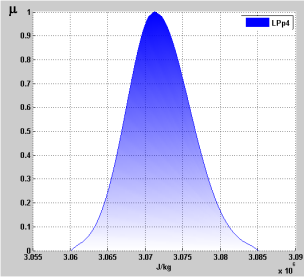

(d)

Figure 4. Fuzzy input parameters of low-pressure section of a steam turbine system (a) $p_{1}$ (Inlet steam flow from boiler superheat section), (b) $p_{2}$ (Inlet steam pressure), (c) $p_{3}$ (Inlet steam flow temperature), (d) $p_{4}$ (Inlet steam flow enthalpy) and (e) $p_{5}$ (Inlet steam flow density).

The uncertain parameter of the low-pressure section shows $\rho_{2}$ has moderate impact of $55 \%$. The uncertainties of $\rho_{1}$ and $\rho_{3}$ show low influences of $31 \%$ and $14 \%$ respectively. The parameters $\rho_{4}$ and $\rho_{5}$ are negligible.

A conclusion that can be made is the influence of inlet steam pressure $\rho_{2}$ confined the high influence measure for each section in the steam turbine system. Following the influence measure of inlet steam flow from the boiler superheat section $\rho_{1}$ and inlet steam flow temperature $\rho_{3}$. However, the inlet steam flow enthalpy $\rho_{4}$ and inlet steam flow density $\rho_{5}$ show only a small influence and can be regarded as negligible.

\section{Application to a furnace system}

A furnace by [9] is considered a complex an uncertain system because it exhibits systemic variability depending on the quantity of inputs. The model's inputs are identified as fuel, air and exhaust gas flows. The following are the state 


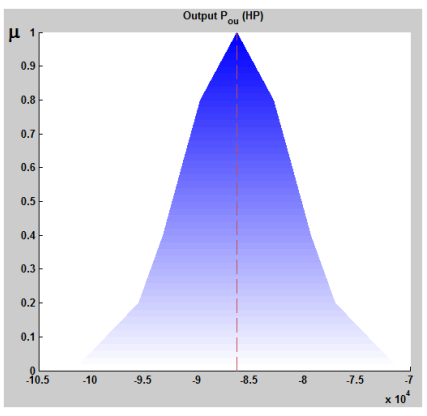

(a)

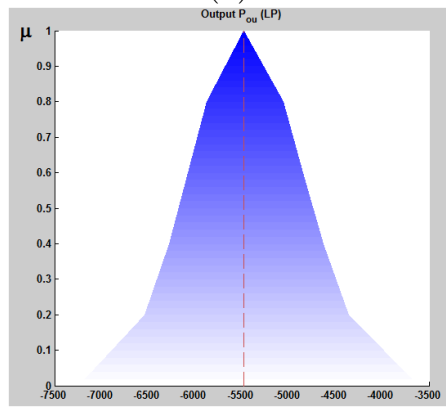

(c)

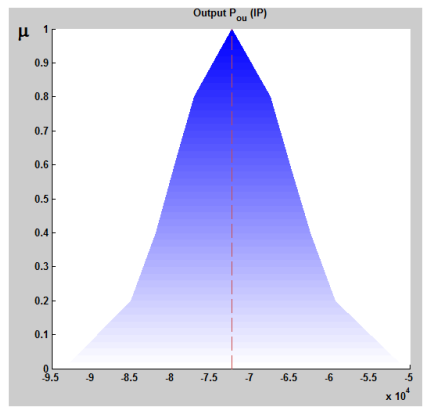

(b)

Figure 5. Fuzzy Output $P_{o u}$ of a Steam Turbine System (a) high-pressure, (b) intermediate-pressure, (c) low-pressure.

space equations [9] for the furnace.

$$
\begin{aligned}
{\left[\begin{array}{c}
\rho_{E G} \\
X_{F 1}
\end{array}\right]=} & {\left[\begin{array}{cc}
-\frac{k_{f} R_{E G} T_{g}}{V_{F}} & 0 \\
-\frac{\left(R_{E G} T_{g}\right)\left(Q_{i r}+Q_{i s}\right)}{V_{F} P_{G}} & -\frac{k_{f} R_{E G} T_{g} R_{S}\left(1+\frac{Y}{100}\right)}{V_{F}}
\end{array}\right]\left(\begin{array}{c}
\rho_{E G} \\
X_{F 1}
\end{array}\right) } \\
& +\left[\begin{array}{ccc}
\frac{1}{V_{F}} & \frac{1}{V_{F}} & \frac{1}{V_{F}} \\
\frac{V_{F}}{V_{F}} & \frac{h_{A}}{V_{F}} & \frac{h_{G}}{V_{F}}
\end{array}\right]\left(\begin{array}{l}
W_{F} \\
W_{A} \\
W_{G}
\end{array}\right)
\end{aligned}
$$

$$
\begin{aligned}
{\left[\begin{array}{c}
Q_{i r} \\
Q_{i s} \\
Q_{r s} \\
Q_{e s} \\
P_{G}
\end{array}\right]=} & {\left[\begin{array}{cc}
\left(\frac{\theta}{1-\theta}\right)\left(Q_{g s}+w_{E G} c_{g s} T_{g r}\right) \frac{R_{E G} T_{g} k_{f}}{w_{E G}} & -\left(\frac{\theta}{1-\theta}\right) \frac{k_{f} R_{E G} C_{g s} T_{g}^{2}}{h_{E G}} \\
\left(Q_{g s}+w_{E G} c_{g s} T_{g r}\right) \frac{R_{E G} T_{g} k_{f}}{w_{E G}} & -\frac{k_{f} R_{E G} c_{g s} T_{g}^{2}}{h_{E G}} \\
k_{f} R_{E G} T_{g} c_{g s}\left(T_{g r}-T_{g e}\right) & 0 \\
k_{f} R_{E G} T_{g} C_{g s}\left(T_{g e}-T_{g l}\right) & 0 \\
R_{E G} T_{g} & 0
\end{array}\right] } \\
& \times\left(\begin{array}{c}
\rho_{E G} \\
X_{F 1}
\end{array}\right) .
\end{aligned}
$$

Equation (4.1) represents the state and equation (4.2) is the output of the furnace. The state parameters of the furnace are $\rho_{E G}$ (the density of exhaust gas from the boiler) and $X_{F 1}$ (the enthalpy and density of exhaust gas from 


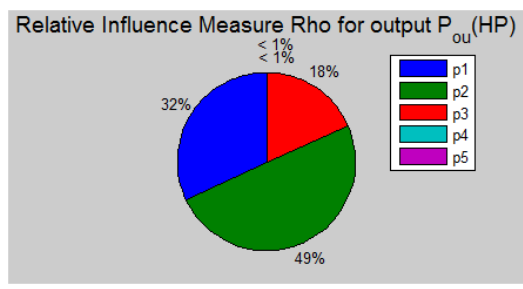

(a)

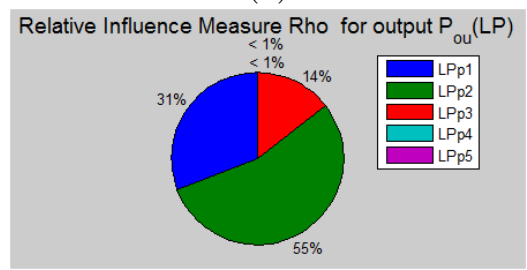

(c)

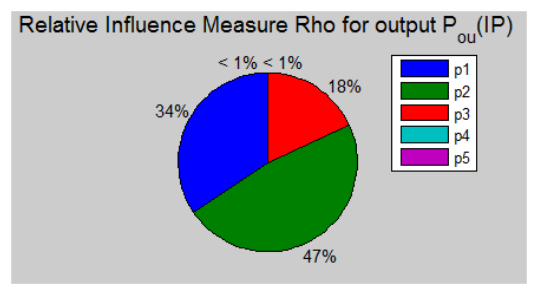

(b)

Figure 6. Relative influence measure $\rho_{i}$ for output $P_{o u}$ in (a) high pressure, (b) intermediate pressure and (c) low pressure section of a steam turbine system.

the boiler). The five output parameters are $Q_{i r}$ (heat transferred to the risers in $\mathrm{J} / \mathrm{s}$ ), $Q_{i s}$ (heat transferred to the superheater in $\mathrm{J} / \mathrm{s}$ ), $Q_{r s}$ (heat transferred to the reheater in $\mathrm{J} / \mathrm{s}$ ), $Q_{e s}$ (heat transferred to the economizer in $\mathrm{J} / \mathrm{s}$ ) and $P_{G}$ (furnace air pressure in $P a$ ). The selected $Q_{i r}$ from equation (4.2) is then solved by using the method of integrating factor:

$$
\begin{gathered}
\mathrm{Q}_{\mathrm{ir}}=\left[\frac{\theta \mathrm{T}_{\mathrm{g}} \mathrm{R}_{\mathrm{EG}} \mathrm{K}_{\mathrm{F}}}{(1-\theta) \mathrm{W}_{\mathrm{EG}}}\left(\mathrm{Q}_{\mathrm{gs}}+\mathrm{W}_{\mathrm{EG}} \mathrm{C}_{\mathrm{gs}} \mathrm{T}_{\mathrm{gr}}\right)\right] \rho_{\mathrm{EG}}-\left[\frac{\theta \mathrm{K}_{\mathrm{F}} \mathrm{R}_{\mathrm{EG}} \mathrm{T}_{\mathrm{g}}^{2} C_{\mathrm{gs}}}{(1-\theta) \mathrm{h}_{\mathrm{EG}}}\right] \mathrm{X}_{\mathrm{F} 1}, \\
\rho_{E G}=\frac{W_{F}+W_{A}+W_{G}}{k_{f} R_{E G} T_{g}}+\mathrm{C} e^{-\frac{\mathrm{K}_{\mathrm{F}} \mathrm{R}_{\mathrm{EG}} \mathrm{T}_{\mathrm{g}}}{\mathrm{V}} t}
\end{gathered}
$$

and in similar way for $X_{F 1}$ :

$$
\begin{gathered}
X_{F 1}=\frac{-\left(Q_{i r}+Q_{i s}\right) R_{E G} T_{g} \rho_{E G} / P_{G}+C_{F} W_{F}+h_{A} W_{A}+h_{G} W_{G}}{k_{f} R_{E G} T_{g} R_{S}(1+Y / 100)} \\
+C e^{-\frac{k_{f} R_{E G} T_{g} R_{S}(1+Y / 100)}{V_{F}} t} .
\end{gathered}
$$

Substitute equations (4.4) and (4.5) into equation (4.3)

$$
\begin{aligned}
\mathrm{Q}_{\mathrm{ir}}= & \left(\frac{\theta}{1-\theta}\right)\left(Q_{g s}+w_{E G} c_{g s} T_{g r}\right) \frac{R_{E G} T_{g} k_{f}}{w_{E G}}\left(\frac{W_{F}+W_{A}+W_{G}}{k_{f} R_{E G} T_{g}}\right. \\
& \left.+C e^{-\frac{\mathrm{K}_{\mathrm{F}} \mathrm{R}_{\mathrm{EG}} \mathrm{T}_{\mathrm{g}}}{\mathrm{V}} t}\right)-\left(\frac{\theta}{1-\theta}\right) \frac{k_{f} R_{E G} C_{g s} T_{g}^{2}}{h_{E G}}\left(C e^{-\frac{k_{f} R_{E G} T_{g} R_{S}(1+Y / 100)}{V_{F}} t}\right. \\
+ & \left.\frac{-\widetilde{W}+C_{F} W_{F}+h_{A} W_{A}+h_{G} W_{G}}{k_{f} R_{E G} T_{g} R_{S}(1+Y / 100)}\right)
\end{aligned}
$$


where

$$
\widetilde{W}=\frac{\left(Q_{i r}+Q_{i s}\right) R_{E G} T_{g}}{P_{G}}\left(\frac{w_{F}+w_{A}+w_{G}}{k_{f} R_{E G} T_{g}}+\mathrm{C} e^{-\frac{\mathrm{K}_{\mathrm{F}} \mathrm{R}_{\mathrm{EG}} \mathrm{T}_{\mathrm{g}}}{\mathrm{V}} t}\right) .
$$

The input parameters for the furnace model are expressed by fuzzy numbers, namely $p_{1}=W_{F}, p_{2}=W_{A}, p_{3}=W_{G}, p_{4}=h_{G}$ and $p_{5}=h_{A}$ as illustrate in Figure 7 .

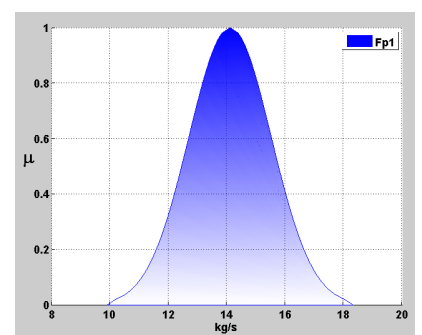

(a)

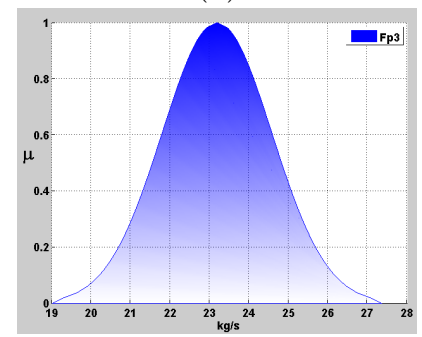

(c)

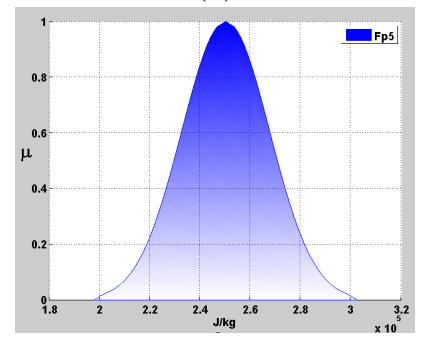

(e)

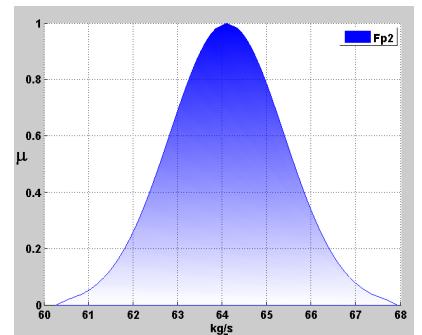

(b)

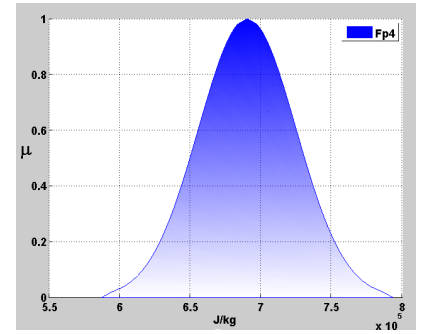

(d)

Figure 7. Fuzzy input parameters of a furnace system (a) $p_{1}=W_{F}$, (b) $p_{2}=W_{A}$, (c) $p_{3}=W_{G}$, (d) $p_{4}=h_{G}$ and (e) $p_{5}=h_{A}$

Figure 8(a) shows the fuzzy value output for $Q_{i r}$, we do not see significant variation in distribution shapes when compared to the original symmetric quasiGaussian distribution of the uncertain parameters $p_{1}, p_{2}, p_{3}, p_{4}$ and $p_{5}$. The parameters $\rho_{i}, \mathrm{i}=1,2,3,4,5$, exhibit non-zero values of influences. Figure 8(b) summarizes the relative influences of input parameters of the furnace system. Only $\rho_{1}$ gives a moderate influence to the system. The parameter $\rho_{2}$ shows low impact on the system. The parameters $\rho_{3}, \rho_{4}$ and $\rho_{5}$ are negligible. 


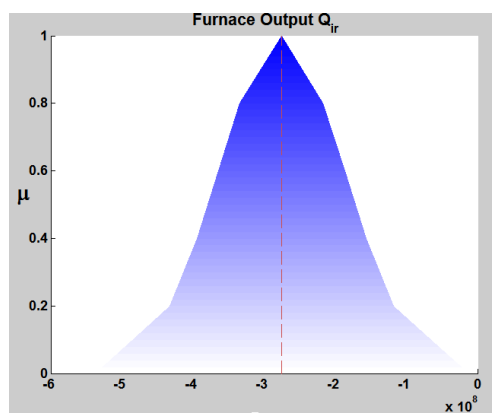

(a)

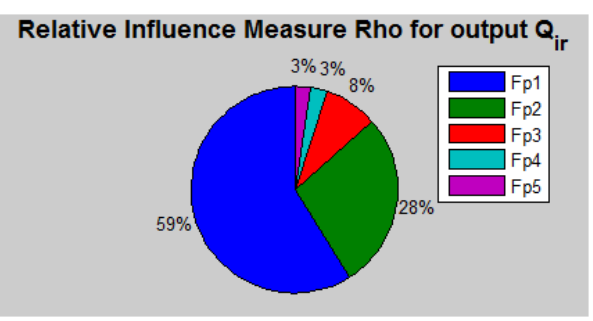

(b)

Figure 8. Results for the furnace system: (a) fuzzy output $Q_{i r}$ of furnace system, (b) relative influence measure $\rho_{i}$ for output $Q_{i r}$.

\section{Application to a reheater system}

A reheater is an important heat exchange component in a high-capacity power plant. The following are the state space equations for a reheater system by [10] of a combined-cycle power plant:

$$
\begin{gathered}
{\left[\begin{array}{c}
\dot{T}_{r h} \\
X_{r h}
\end{array}\right]=\left[\begin{array}{cc}
-\frac{K_{r h} W_{r i}^{0.8}}{M_{r} C_{r i}} & 0 \\
\frac{K_{r r} W_{r i}^{\gamma / 8}}{V_{r h}} & -\frac{W_{r o}}{V_{r h} \rho_{r h}}
\end{array}\right]\left(\begin{array}{c}
T_{r h} \\
X_{r h}
\end{array}\right)} \\
+\left[\begin{array}{ccc}
\frac{1}{M_{r} C_{r h}} & 0 & \frac{K_{r h} T_{r}}{M_{r} C_{r h} W_{0.2}^{0}} \\
0 & \frac{W_{r i}}{V_{r h}} & -\frac{K_{r h} T_{r}^{2}}{V_{r h} W_{r i}^{0}}
\end{array}\right]\left(\begin{array}{c}
Q_{r s} \\
h_{r i} \\
W_{r i}
\end{array}\right), \\
{\left[\begin{array}{c}
P_{r o} \\
T_{r}
\end{array}\right]=\left[\begin{array}{cc}
0 & R_{r}\left[\frac{h_{r o}-h_{r e f}+C_{p r} T_{r e f}}{h_{r o} C_{p r}}\right. \\
1 & 0
\end{array}\right]\left(\begin{array}{c}
T_{r h} \\
X_{r h}
\end{array}\right) .}
\end{gathered}
$$

Equation (5.1) represents the state and equation (5.2) is the output of the reheater. The state parameters of the reheater model consists of $T_{r h}$ (reheater metal tube temperature) and $X_{r h}$ (specific enthalpy of outlet steam and steam density). The two output parameters are $P_{r o}$ (outlet steam pressure) and $T_{r}$ (reheated steam temperature). For this work, reduction of the reheater model involves selecting the output parameter $T_{r}$ from Equation (5.2) by using integrating factor

$$
P_{r o}=R_{r}\left[\frac{h_{r o}-h_{r e f}+C_{p r} T_{r e f}}{h_{r o} C_{p r}}\right] X_{R H} .
$$

From Equation (5.1), $X_{R H}$ is deduced from ordinary equation

$$
\frac{d X_{R H}}{d t}=\frac{K_{r h} W_{r i}^{0.8}}{V_{r h}} T_{r h}-\frac{W_{r o}}{V_{r h} \rho_{r h}} X_{R H} \frac{W_{r i}}{V_{r h}} h_{r i}-\frac{K_{r h} T_{r}}{V_{r h} W_{r i}^{0.2}} W_{r i},
$$


After simple computations we get:

$$
X_{R H}=\frac{K_{r h} W_{r i}^{0.8} T_{r h}+W_{r i} h_{r i}-\frac{K_{r h} T_{r}}{W_{r i}^{0}{ }^{2}} W_{r i}}{\frac{W_{r o}}{\rho_{r h}}}+C e^{-\frac{W_{r o}}{V_{r h} \rho_{r h}} t} .
$$

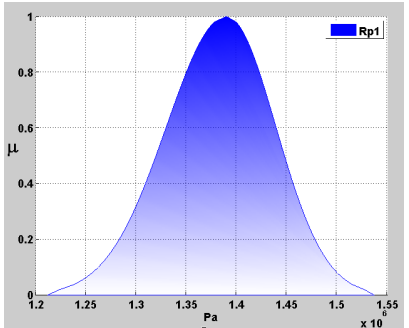

(a)

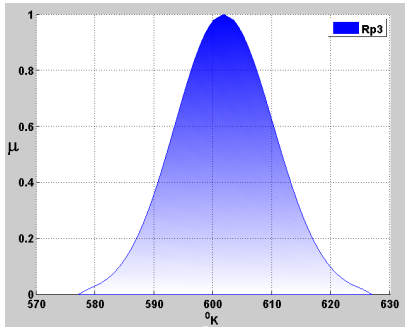

(c)

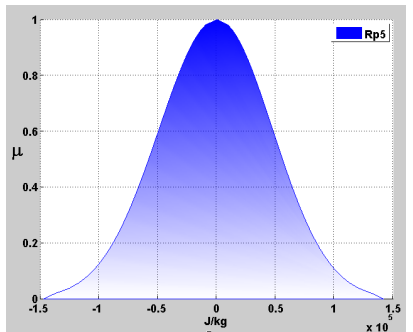

(e)

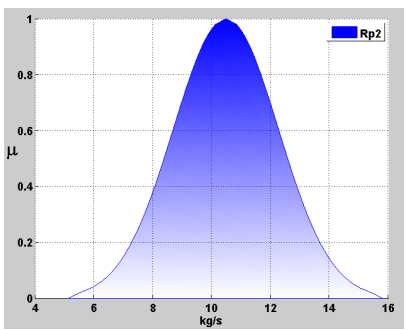

(b)

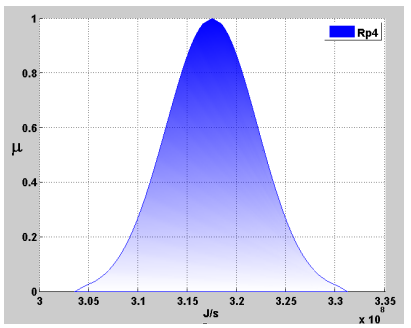

(d)

Figure 9. Fuzzy input parameters of reheater system (a) $p_{1}=P_{r i}$, (b) $p_{2}=W_{r i}$, (c) $p_{3}$ $=T_{r i}$, (d) $p_{4}=Q_{r s}$ and (e) $p_{5}=h_{r i}$

Next, the model parameter of $T_{r h}$ is determined from the following equation

$$
\frac{d T_{r h}}{d t}=-\frac{K_{r h} W_{r i}^{0.8}}{M_{r} C_{r h}} T_{r h}+\frac{1}{M_{r} C_{r h}} Q_{r s}+\frac{K_{r h} T_{r}}{M_{r} C_{r h} W_{r i}^{0.2}} W_{r i},
$$

after simple computations we get:

$$
T_{r h}=\frac{Q_{r s}+\frac{K_{r h} T_{r}}{W_{r i}^{2}} W_{r i}}{K_{r h} W_{r i}^{0.8}}+C e^{-\frac{K_{r h} W_{r i}^{0.8}}{M_{r} C_{r h}} t} .
$$


Substitute equation (5.4) and (5.5) into equation (5.3) gives

$$
\begin{aligned}
P_{r o}= & R_{r}\left[\frac{h_{r o}-h_{r e f}+C_{p r} T_{r e f}}{h_{r o} C_{p r}}\right] \\
& \times\left(\frac{\rho_{r h} Q_{r s}}{W_{r o}}+\frac{\rho_{r h} W_{r i} h_{r i}}{W_{r o}}+\frac{\rho_{r h} K_{r h} W_{r i}^{0.8} C e^{-\frac{W_{r o}}{V_{r h} \rho_{r h}} t}}{W_{r o}}+C e^{-\frac{K_{r h} W_{r i}^{0.8}}{M_{r} C_{r h}} t}\right) .
\end{aligned}
$$

The input parameters for the reheater model are expressed by fuzzy numbers $p_{1}, p_{2}, p_{3}, p_{4}$ and $p_{5}$ as illustrated in Figure 9.

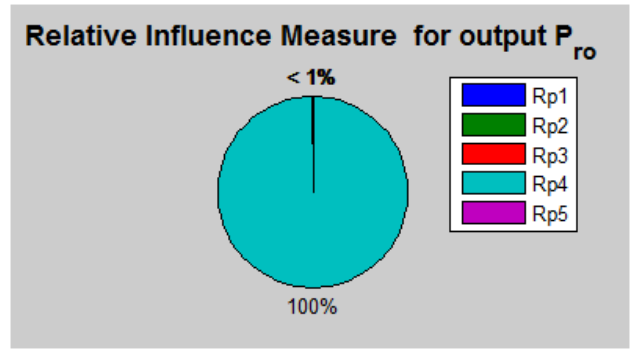

Figure 10. Relative influence measure $\rho_{i}$ for output $P_{r_{o}}$ in reheater system.

Regarding the influence of input parameters $\rho_{i}, i=1,2, \ldots, 5$, the breakdown in Figure 10 indicates only one out of the five uncertain input parameters exerts influence on the outflow of the reheater. The parameter $\rho_{4}$ shows significant influence on the output of the reheater compare to other parameters.

\section{Conclusions}

The general transformation method is used for steam turbine and boiler systems to analyze and quantify the influences of their input parameters.

\section{Acknowledgements}

The authors are thankful to Universiti Teknologi Malaysia for providing the necessary environment, technical support and funding for this research. FRGS. $4 \mathrm{~F} 756$.

\section{References}

[1] A. Chaibakhsh and A. Ghaffari. Steam turbine model. Simulation Modelling Practice and Theory, 16(9):1145-1162, 2008. https://doi.org/10.1016/j.simpat.2008.05.017.

[2] M. Hanss. The transformation method for the simulation and analysis of systems with uncertain parameters. Fuzzy Sets and Systems, 130(3):277-289, 2002. https://doi.org/10.1016/S0165-0114(02)00045-3.

[3] M. Hanss. Applied Fuzzy Arithmetic. An Introduction with Engineering. Springer, Berlin, 2005. https://doi.org/10.1007/b138914. 
[4] M. Hanss and O. Nehls. Simulation of the human glucose metabolism using fuzzy arithmetic. In PeachFuzz 2000. 19th International Conference of the North American Fuzzy Information Processing Society - NAFIPS (Cat. No.00TH8500), pp. 201-205, 2000. https://doi.org/10.1109/NAFIPS.2000.877420.

[5] M. Hanss and O. Nehls. Enhanced parameter identification for complex biomedical models on the basis of fuzzy arithmetic. In Proceedings Joint 9th IFSA World Congress and 20th NAFIPS International Conference (Cat. No. 01TH8569), volume 3, pp. 1631-1636, 2001. https://doi.org/10.1109/NAFIPS.2001.943795.

[6] M. Hanss and S. Turrin. A fuzzy-based approach to comprehensive modeling and analysis of systems with epistemic uncertainties. Structural Safety, 32(6):433441, 2010. https://doi.org/10.1016/j.strusafe.2010.06.003.

[7] N.A. Harish, R. Ismail and T. Ahmad. Graphical representation of fuzzy state space of a boiler system. In Proc. of the 11th WSEAS Int. Conf. on Neural Networks, NN'10, Proceedings of the 11th WSEAS Int. Conf. on Evolutionary Computing, EC'10, Proc. of the 11th WSEAS Int. Conf. on Fuzzy Systems, FS'10, pp. 99-103, Iasi, Romania, 2010. World Scientific and Engineering Academy and Society (WSEAS) Stevens Point, Wisconsin, USA.

[8] I.U. Khan, T. Ahmad and N. Maan. Feedback fuzzy state space modeling and optimal production planning for steam turbine of a combined cycle power generation plant. Research Journal of Applied Science, 7(2):100-107, 2012. https://doi.org/10.3923/rjasci.2012.100.107.

[9] W.M. Wan Munirah, T. Ahmad, S. Ahmad and A. Ashaari. Simulation of furnace system with uncertain parameter. Malaysian Journal of Fundamental and Applied Sciences, 11(1):5-9, 2015. https://doi.org/10.11113/mjfas.v11n1.334.

[10] W.M. Wan Munirah, T. Ahmad, A. Ashaari and M. Adib Abdullah. Modeling fuzzy state space of reheater system for simulation and analysis. In AIP Conference Proceedings, volume 1605, pp. 488-493, Malaysia, 2014. AIP. https://doi.org/10.1063/1.4887637.

[11] W.M. Wan Munirah, A. Tahir and A. Azmirul. Identifying the uncertain model parameter of a steam turbine system. Pertanika Journal of Science and Technology, 25(2):545-560, 2017.

[12] A. Ordys, A.W. Pike, M.A. Johnson, R.M. Katebi and M.J. Grimble. Modelling and Simulation of Power Generation Plants. Advances in Industrial Control. Springer-Verlag, London, 1994. https://doi.org/10.1007/978-1-4471-2114-5. 


\section{Appendix}

\begin{tabular}{|c|c|c|c|}
\hline \multicolumn{4}{|c|}{ Parameters of a Steam Turbine System } \\
\hline $\mathbf{P}$ & Parameter & Unit & Definition \\
\hline \multicolumn{4}{|c|}{ High Pressure } \\
\hline $\mathrm{P}_{1}$ & $W_{\text {in }}$ & $\mathrm{kg} / \mathrm{s}$ & Inlet steam flow from boiler superheat section \\
\hline $\mathrm{P}_{2}$ & $P_{\text {in }}$ & $P a$ & Inlet steam pressure \\
\hline $\mathrm{P}_{3}$ & $T_{i n}$ & ${ }^{o} K$ & Inlet steam flow temperature \\
\hline $\mathrm{P}_{4}$ & $h_{i n}$ & $\mathrm{~J} / \mathrm{kg}$ & Inlet steam flow enthalpy \\
\hline $\mathrm{P}_{5}$ & $\rho_{\text {in }}$ & $K g / m^{3}$ & Inlet steam flow density \\
\hline \multicolumn{4}{|c|}{ Intermediate Pressure } \\
\hline $\mathrm{P}_{1}$ & $W_{\text {inIP }}$ & $\mathrm{kg} / \mathrm{s}$ & Inlet steam flow from boilerreheater section \\
\hline $\mathrm{P}_{2}$ & $P_{o}$ & $P a$ & Inlet steam pressure \\
\hline $\mathrm{P}_{3}$ & $T_{o}$ & ${ }^{o} K$ & Inlet steam flow temperature \\
\hline $\mathrm{P}_{4}$ & $h_{o}$ & $J / k g$ & Inlet steam flow enthalpy \\
\hline $\mathrm{P}_{5}$ & $\rho_{o}$ & $K g / m^{3}$ & Inlet steam flow density \\
\hline \multicolumn{4}{|c|}{ Low Pressure } \\
\hline $\mathrm{P}_{1}$ & $W_{i n L P}$ & $\mathrm{~kg} / \mathrm{s}$ & Inlet steam flow from IP section \\
\hline $\mathrm{P}_{2}$ & $P_{i n L P}$ & $P a$ & Inlet steam pressure \\
\hline $\mathrm{P}_{3}$ & $T_{\text {inLP }}$ & ${ }^{o} K$ & Inlet steam flow temperature \\
\hline $\mathrm{P}_{4}$ & $h_{i n L P}$ & $\mathrm{~J} / \mathrm{kg}$ & Inlet steam flow enthalpy \\
\hline $\mathrm{P}_{5}$ & $\rho_{\text {inLP }}$ & $K g / m^{3}$ & Inlet steam flow density \\
\hline \multicolumn{4}{|c|}{ Parameters of a Furnace System } \\
\hline $\mathbf{P}$ & Parameter & Unit & Definition \\
\hline $\mathrm{P}_{1}$ & $w_{F}$ & $\mathrm{~kg} / \mathrm{s}$ & Fuel flow to the furnace \\
\hline $\mathrm{P}_{2}$ & $w_{A}$ & $\mathrm{~kg} / \mathrm{s}$ & Air flow to the furnace \\
\hline $\mathrm{P}_{3}$ & $w_{G}$ & $\mathrm{~kg} / \mathrm{s}$ & Exhaust gas flow from the gas turbine \\
\hline $\mathrm{P}_{4}$ & $h_{G}$ & $\mathrm{~J} / \mathrm{kg}$ & Enthalpy of exhaust gas from the gas turbine \\
\hline $\mathrm{P}_{5}$ & $h_{A}$ & $\mathrm{~J} / \mathrm{kg}$ & Inlet air enthalpy \\
\hline $\mathrm{P}_{6}$ & $\theta$ & rad & Tilt angle coefficient \\
\hline $\mathrm{P}_{7}$ & $T_{s t}$ & ${ }^{o} K$ & Temperature of superheater metal tubes \\
\hline $\mathrm{P}_{8}$ & $T_{r h}$ & ${ }^{o} K$ & Temperature of reheater metal tubes \\
\hline $\mathrm{P}_{9}$ & $T_{e t}$ & ${ }^{o} K$ & Temperature of economizer metal tubes \\
\hline \multicolumn{4}{|c|}{ Parameters of a Reheater System } \\
\hline $\mathbf{P}$ & Parameter & Unit & Definition \\
\hline $\mathrm{P}_{1}$ & $P_{r i}$ & $P a$ & Inlet steam pressure (from the steamturbine) \\
\hline $\mathrm{P}_{2}$ & $W_{r i}$ & $\mathrm{~kg} / \mathrm{s}$ & Reheater inlet steam mass flow \\
\hline $\mathrm{P}_{3}$ & $T_{r i}$ & ${ }^{o} K$ & Inlet steam temperature (from the steam turbine) \\
\hline $\mathrm{P}_{4}$ & $Q_{r s}$ & $J / s$ & $\begin{array}{l}\text { Heat supplied to the reheater (from the steam tur- } \\
\text { bine) }\end{array}$ \\
\hline $\mathrm{P}_{5}$ & $h_{r i}$ & $\mathrm{~J} / \mathrm{kg}$ & Inlet steam specific enthalpy \\
\hline
\end{tabular}

